Article

\title{
An Innovative Design of a Microtab Deployment Mechanism for Active Aerodynamic Load Control
}

\author{
Kuo-Chang Tsai ${ }^{1,2}$, Cheng-Tang Pan ${ }^{1}$, Aubryn M. Cooperman ${ }^{2}$, Scott J. Johnson ${ }^{2}$ and \\ C. P. van Dam ${ }^{2, *}$
}

1 Department of Mechanical \& Electro-Mechanical Engineering, National Sun Yat-sen University, No. 70 Lien-hai Rd., Kaohsiung 80424, Taiwan; E-Mails: vongohking@yahoo.com.tw (K.-C.T.); panct@mail.nsysu.edu.tw (C.-T.P.)

2 Department of Mechanical \& Aerospace Engineering, University of California - Davis, One Shields Avenue, Davis, CA 95616, USA; E-Mails: amcooperman@ucdavis.edu (A.M.C.); sjjohnson@ucdavis.edu (S.J.J.)

* Author to whom correspondence should be addressed; E-Mail: cpvandam@ucdavis.edu; Tel.: +1-530-752-7741 or +1-530-752-0580.

Academic Editor: Frede Blaabjerg

Received: 6 May 2015 / Accepted: 8 June 2015 / Published: 17 June 2015

\begin{abstract}
This study presents an innovative design of a microtab system for aerodynamic load control on horizontal-axis wind-turbine rotors. Microtabs are small devices located near the trailing edge of the rotor blades and enable a rapid increase or decrease of the lift force through deployment of the tabs on the pressure or suction side of the airfoil, respectively. The new system has been designed to replace an earlier linearly-actuated microtab mechanism whose performance was limited by space restrictions and stiction. The newly-designed microtab system is based on a four-bar linkage that overcomes the two drawbacks. Its improved kinematics allows for the tab height to increase from $1.0 \%$ to $1.7 \%$ of the airfoil chord when fully deployed, thereby making it more effective in terms of aerodynamic load control. Furthermore, the modified four-bar link mechanism provides a more robust and reliable mechanical structure.
\end{abstract}

Keywords: wind turbine rotor; aerodynamic load control; microtab; four-bar linkage 


\section{Introduction}

Wind turbines have been used to convert wind energy worldwide. As the most accessible sites with the best wind resources are rapidly being occupied, wind turbines are beginning to be installed in locations with lower wind speeds or less accessibility, such as offshore sites [1]. Wind turbines installed at lower wind speed locations provide less wind energy productivity, while wind turbines installed at less accessible locations make the construction and maintenance more costly. Therefore, to increase the energy capture and to reduce the cost, improvements in wind turbine design become critical.

The need to reduce the cost of wind energy leads to a demand for larger rotors in order to increase wind capture at greater heights. The increase of the blade size causes more demands on the structure, including supporting and component structures, leading to an increase in cost, unless the blade loads can be reduced. Active aerodynamic load control is proposed to reduce these fluctuating loads by rapidly changing the aerodynamic characteristics of a blade section, altering the blade's aerodynamic response according to changes in wind conditions. Effective aerodynamic control of unwanted loads can lead to lower ultimate and fatigue loads along the blade. Minimizing blade-root loads will have a positive impact on other turbine components (e.g., gearbox, main shaft, tower), thus leading to a more reliable turbine and longer lasting components [1,2]. If blade fatigue loads are reduced, the lifetime of the turbine can be significantly prolonged. By extending the lifetime of a conventional $1.5 \mathrm{MW}$ wind turbine by one year, approximately $\$ 200,000$ in additional electric energy can be captured. This results in a reduction of the overall cost of energy on a per-turbine basis, thereby making wind energy more competitive [3].

Various devices have been proposed for active aerodynamic load control [4]. This paper focuses on microtabs [1,5-8]. The microtab is based on the same concept as the Gurney flap, which changes the aerodynamic characteristics by altering the blade's airfoil section geometry in the trailing edge region [9]. Traditional Gurney flaps are fixed at the trailing edge, but microtabs are actively controlled and located just forward from the trailing edge in order to have enough space to retract (Figure 1). They can be applied to the suction side of an airfoil to decrease lift or to the pressure side to increase lift. Their small size ( $1 \%$ to $2 \%$ of the chord length, the order of the boundary-layer thickness) allows them to deploy rapidly, while still producing a shift in the lift coefficient of 0.1 or more in either direction [1]. However, the space in the trailing-edge region of typical airfoils is very limited, as shown in Figure 2. This limited space impacts the design and performance of the microtab, since it is difficult to install. Because of the limited space, the microtab system has to be small, and its manufacturing has to be precise.

The dynamic response of an airfoil model with linearly-actuated microtabs was tested at the University of California Davis (UCD) Aeronautical Wind Tunnel [1,2]. Although the tests were successful, it was determined that the existing microtab system had two drawbacks that impacted its aerodynamic performance. First, the microtab height was insufficient when fully deployed, thereby limiting the device's change of the lift coefficient. Second, the actuating mechanism uses a single supporting lever arm, which resulted in too much flexibility and caused stiction during tab deployment. The innovative microtab presented here conquers two major difficulties in existing microtabs: First, it allows the tab height to increase from $1.0 \%$ chord to $1.7 \%$ chord, thereby enhancing its effectiveness in controlling lift. Second, it allows for the microtab deployment and support system to be more robust, thereby enhancing its reliability. 
In the following sections, the microtab and its effects on airfoil lift are outlined, and the newly-designed microtab mechanism is presented.

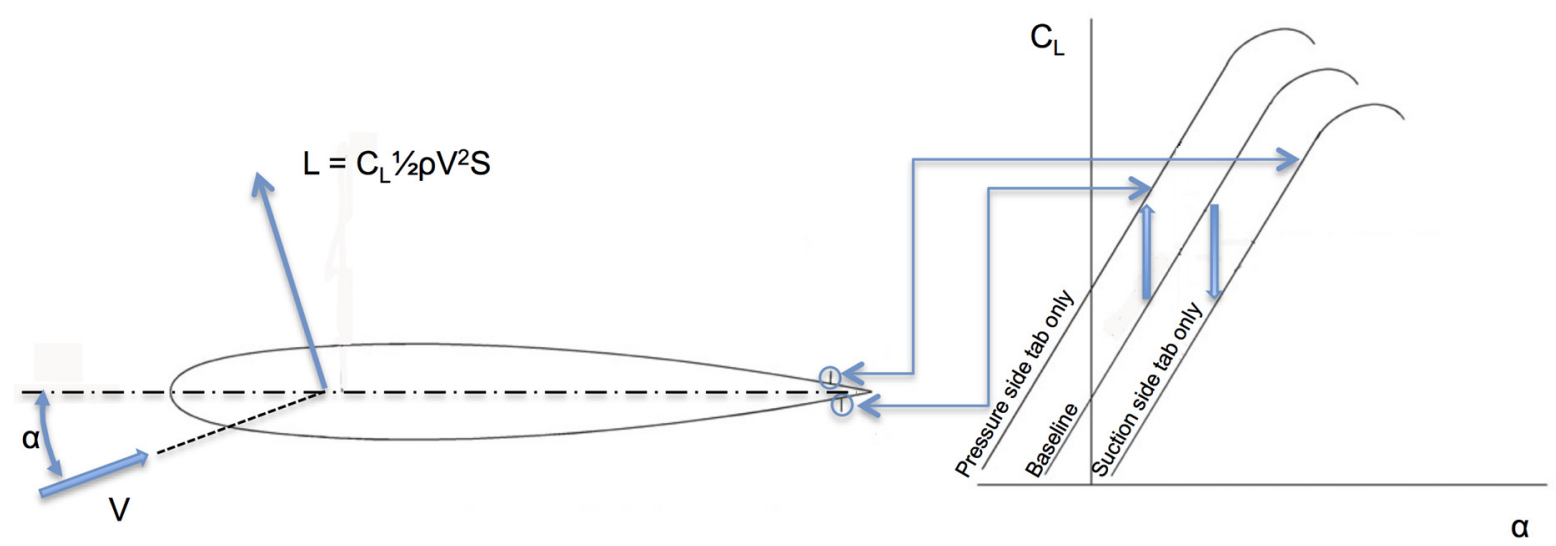

Figure 1. Actively-controlled microtab concept and the effect of tab deployment on lift. The letters and symbols L, $\mathrm{C}_{\mathrm{L}}, \rho, \mathrm{V}$ and $\mathrm{S}$ are total lift, lift coefficient, air density, air speed and planform area, respectively.

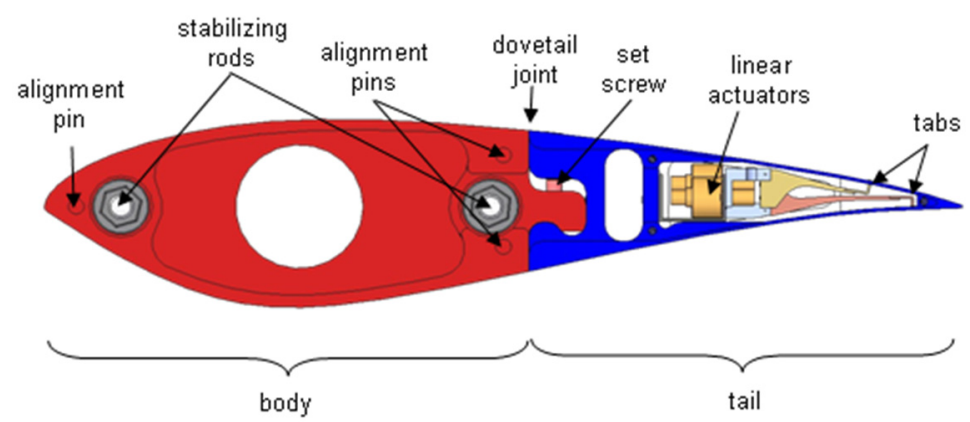

(a)

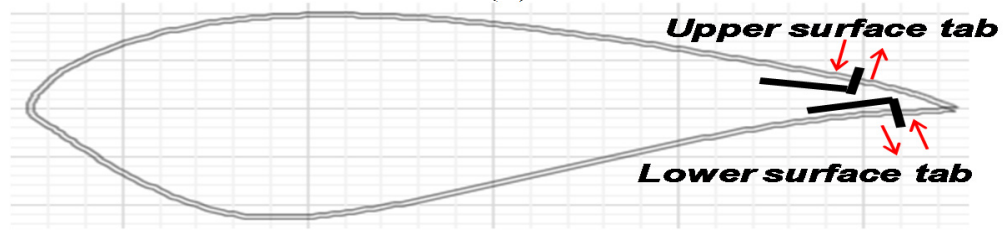

(b)

Figure 2. (a) Diagram showing the microtab system in the trailing-edge region of the airfoil; (b) Drawing of the airfoil with tabs extended on the upper and lower surfaces.

\section{Design of Existing Microtab System}

\subsection{Microtab}

The existing microtab system tested at the UCD [8] involves small tabs that are deployed perpendicular to the blade surface, near the trailing edge of the wind turbine airfoil (Figures 2 and 3). The fully-deployed height (measured from the airfoil surface) of a microtab is about $1 \%$ chord, which is at the lower end of the boundary-layer thickness (1\% to $2 \%$ chord). A tab height higher than the boundary layer thickness creates more lift, but also increases drag, while a height much lower than $1 \%$ chord is not effective [10]. 
The tabs are installed on the upper (suction side) and lower (pressure side) surfaces of the blade to produce different aerodynamic effects. Lift enhancement is achieved by deploying tabs on the lower surface, and lift mitigation is achieved by deploying tabs on the upper surface.

Computational and experimental results show that tabs at the lower surface have to be placed close to the trailing edge of the blade [11]. However, the space within the airfoil becomes smaller and smaller as tab placement approaches the trailing edge, making it difficult to accommodate a retracted tab. Previous studies have shown that the tab should be placed between $0 \%$ to $10 \%$ chord from the trailing edge to remain effective [6-8,10-12]. A lower surface tab with a tab height of $1 \%$ chord positioned at $5 \%$ chord upstream from the trailing edge (or at the $95 \%$ chord location from the leading edge) provides the best combination in terms of tab lift effectiveness, drag and available trailing-edge volume [11].

Microtabs located on the upper surface can be used to mitigate lift and alleviate bending loads created by wind turbulence. The location on the upper surface is not as restrictive as the lower surface. However, the tab location around $90 \%$ chord tends to have a greater lift-mitigating effect for angles of attack in the linear lift regime. The optimum location of the upper tab depends on the application. For the purposes of this study, an upper surface tab located farther aft is more effective, and thus, a location of $90 \%$ chord was selected [10].

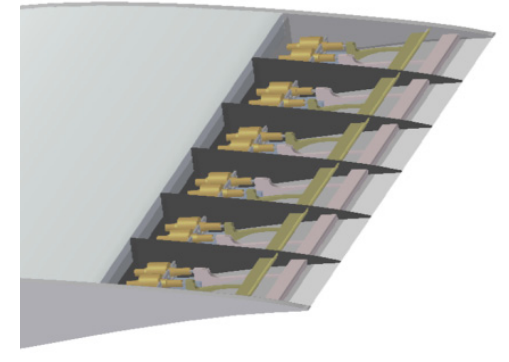

(a)

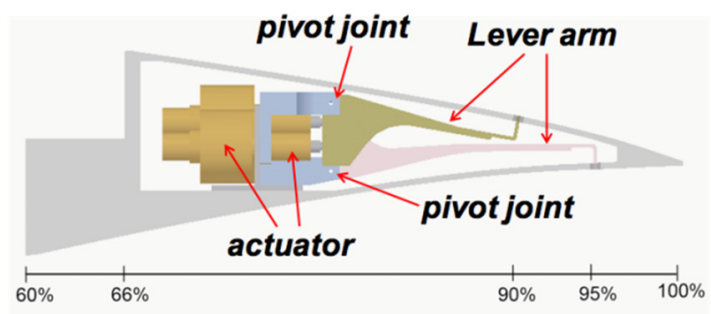

(c)

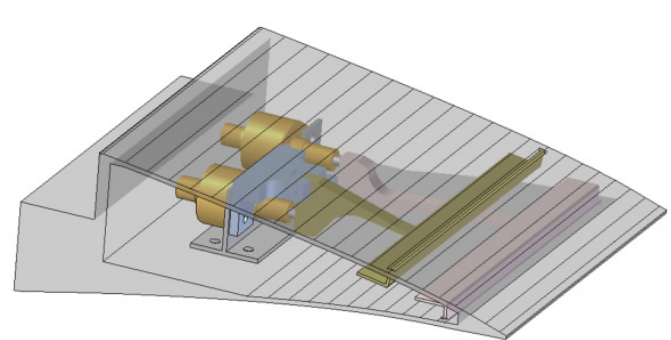

(b)

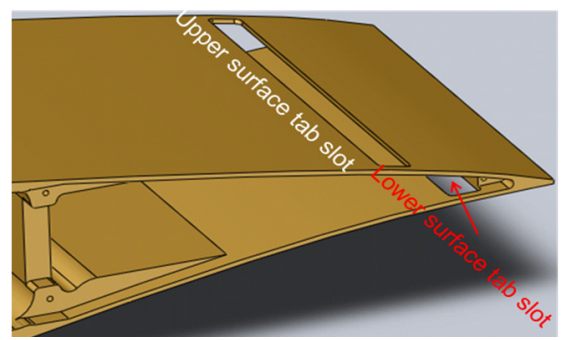

(d)

Figure 3. (a) Six bays at the tail of the wind tunnel model of a modified S819 airfoil that contain the microtab actuation systems; (b) model of one bay housing a microtab actuation system; (c) the side view of a bay containing a microtab actuation system with the upper surface tab in foreground; (d) the tail part of the wind tunnel model. The slots on each surface are where the microtabs are deployed into and retracted from the air flow.

\subsection{Bay Design and Actuation Design}

A wind tunnel model based on the modified S819 airfoil was constructed to house six microtab bays in the spanwise direction (Figure 3a). Each bay had one upper surface tab and one lower surface tab, 
and they were connected to each other (Figure 3a-c). The bay design makes the wind tunnel model of the modified S819 airfoil modularized and flexible. Another advantage of the bay design for wind-tunnel testing is that air leakage from the pressure side to the suction side of the airfoil occurs bay-by-bay, instead of involving the entire model, thus reducing the air leakage. Figure $3 \mathrm{~b}$ shows a close-up of one bay. The two actuators were bolted to a bracket, which was mounted to the lower surface of the airfoil. The actuator and the tab were connected by a lever arm (Figure 3c).

The linear actuators push and pull the lever arm to deploy and retract the tabs through slots (Figure $3 \mathrm{~d}$ ). The lever arm mechanism is a simple design that converts the actuator's horizontal motion into a vertical motion for the tab by rotating about a single pivot joint (Figure 3c).

\section{Results from Existing Microtabs}

The wind tunnel model with the actively-controlled tabs was installed and tested in the UC Davis wind tunnel [1,2]. In Figure 4a, the model with the tabs retracted is depicted installed vertically in the wind tunnel test section. Figure $4 \mathrm{~b}$ provides a detailed view of the model with the tabs deployed on the lower surface (pressure side) of the model.

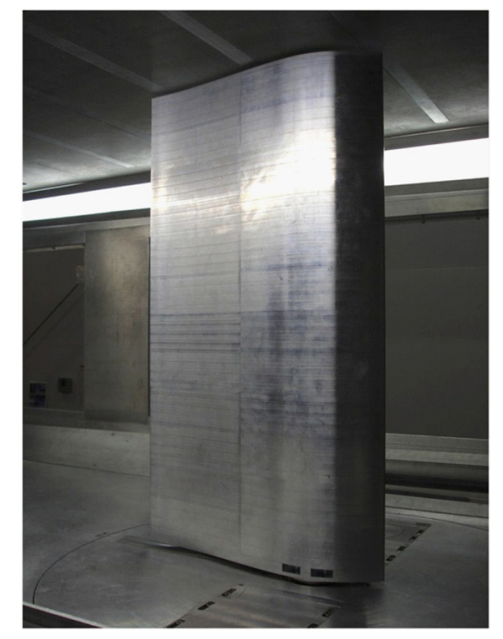

(a)

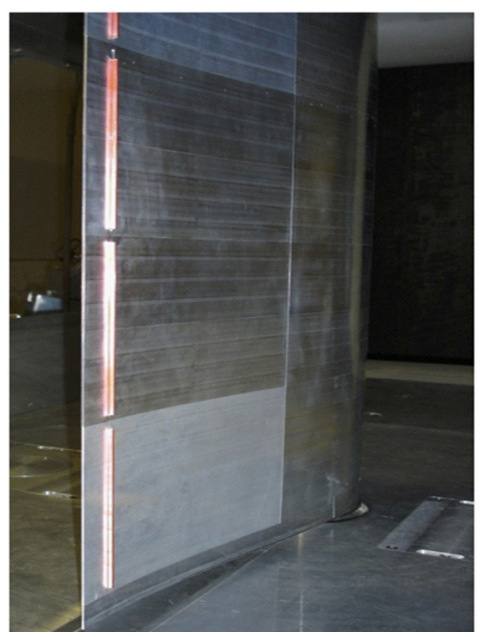

(b)

Figure 4. (a) Model-based modified S819 section shape in wind tunnel test section (tabs retracted); (b) The model mounted in the wind tunnel with tabs deployed on the lower surface (pressure side).

The model was connected to the force balance, and Figure 5 shows the lift coefficient as a function of the angle of attack for the baseline configuration (tabs retracted) and with tabs deployed on the upper and lower surface, respectively. Note that results in Figure 5, as well as in Figure 6, are associated with the existing design. The results demonstrate the range of lift variation, $\Delta \mathrm{C}_{\mathrm{L}}$, achievable with the tab actuation system described above.

In addition to investigating the static performance of all six tabs deployed together, individual tab deployments were also examined. Tabs are labeled starting with 1 at the top of the model as mounted in the tunnel. Figure 6 shows the change in lift for each individual tab as a percentage of the total change in lift observed when all six tabs were deployed. The two outer tabs, 1 and 6, were only half as effective as the center four tabs due to the interaction with the floor and ceiling of the test section. 
Tufts applied to the airfoil without tabs showed areas of disturbed flow at these locations. The central tabs each accounted for slightly over $20 \%$ of the total $\Delta \mathrm{C}_{\mathrm{L}}$, with the exceptions of Tab 3 on the lower surface and Tab 5 on the upper surface. The deployed height of each of these tabs falls below the average tab height: the lower surface Tab 3 was $0.18 \mathrm{~mm}$ short of the average, and the upper surface Tab 5 was $0.5 \mathrm{~mm}$ short of the average. This reduction in height decreased the contribution of these two tabs to $18 \%$ and $19 \%$ of the total $\Delta \mathrm{C}_{\mathrm{L}}$, respectively. The inconsistency in tab deployment was largely the result of the tab deployment mechanism that caused too much flexibility. This leads to the development of a more robust deployment system described in the next sections.

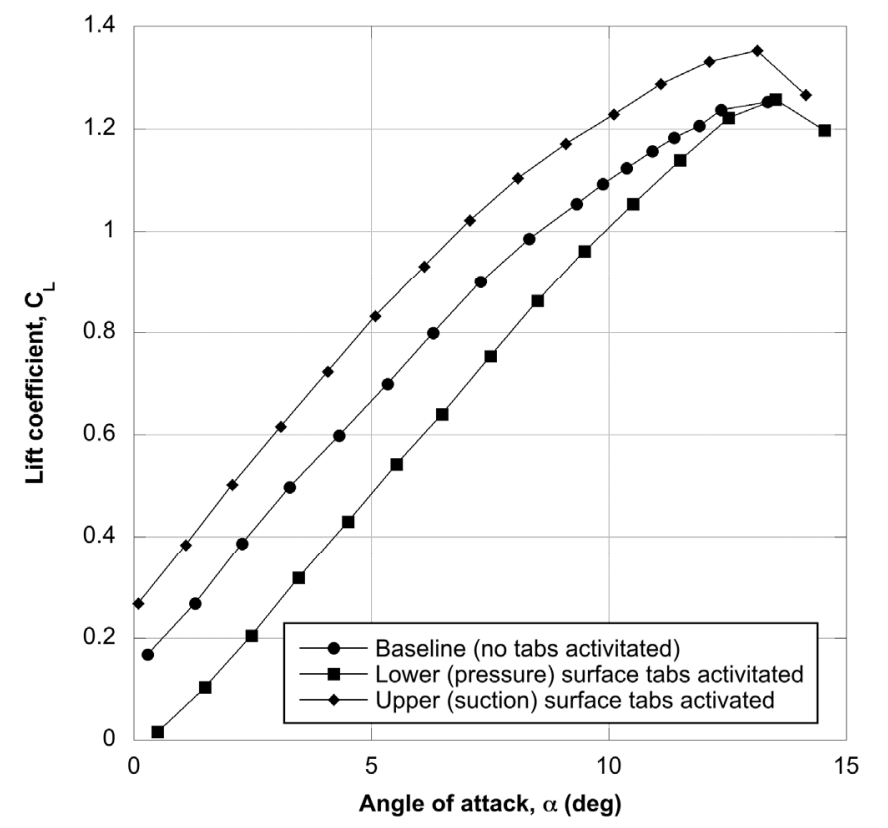

Figure 5. Effect of tab deployment on the model lift coefficient at $\mathrm{Re}=1.0 \times 10^{6}[13]$.

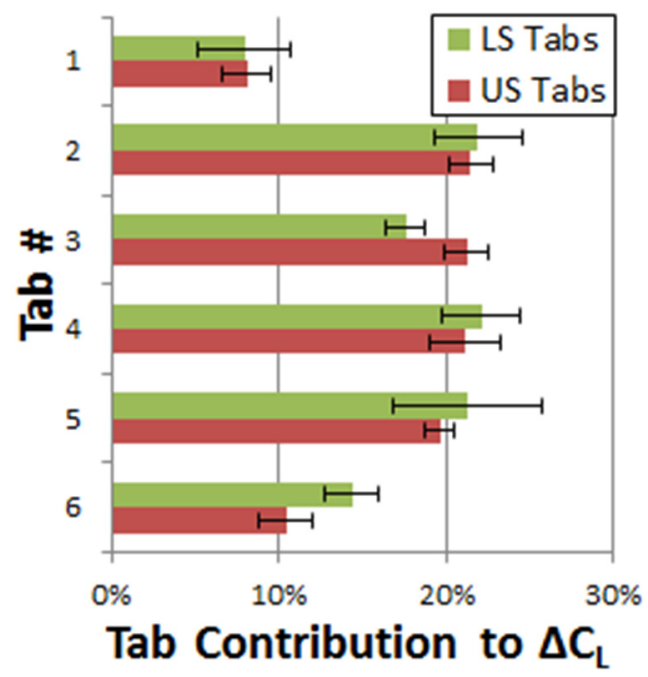

Figure 6. Individual tab contribution to the change in the lift coefficient depicted in Figure 5 [13]. LS and US indicate Lower Surface and Upper Surface, respectively. The symbol \# is number. 


\section{A New Innovative Design of a Microtab}

The existing microtab system was able to provide valuable validation information for actively-deployed devices during wind tunnel tests. However, the system design had two main drawbacks. First, the fully-deployed tab height only reaches $1 \%$ chord, about the lower end of the boundary layer thickness variation, while the desired tab height is between $1 \%$ to $2 \%$ chord. Second, existing microtabs do not possess a robust structure, which reduces their reliability. The limitation of $1 \%$ chord stems from the available space within an airfoil at the $95 \%$ chord location, where a lower surface tab currently deploys along the normal direction of the blade surface.

In this study, we propose a new design of a microtab to overcome both drawbacks. We use the concept of a four-bar linkage to (1) increase the fully-deployed tab height to $1.7 \%$ chord by deploying a longer microtab along a curved, instead of a straight-line, trajectory normal to the airfoil surface and (2) stabilize the microtab mechanism by forming a robust spatial structure.

\subsection{The Newly-Designed Microtab}

As designed in Cooperman et al. [2], and as mentioned earlier, the upper surface tab was located at $90 \%$ chord, while the lower surface tab was located at $95 \%$ chord. This means that the upper surface tab had more available space than the lower tab for its retraction. Thus, our design and discussion for the new microtab focuses on the lower surface tab because the design of the upper surface tab became trivial once the more restrictive spatial constraints for the lower tab were overcome.

The new microtab was developed based on the concept of a four-bar linkage. Figure $7 \mathrm{a}$ shows the features of a basic four-bar linkage, which include a ground link $(\overline{\mathrm{PQ}})$, an input link $(\overline{\mathrm{PA}})$, a coupler link $(\overline{\mathrm{AB}})$ and an output link $(\overline{\mathrm{QB}})$. Positions $\mathrm{A}$ and $\mathrm{B}$, two ends of the coupler link, are the pivot joints for the input link and the output link, respectively. The ground link $(\overline{\mathrm{PQ}})$ will be represented by the inner skin of the lower surface of the wind-tunnel model.

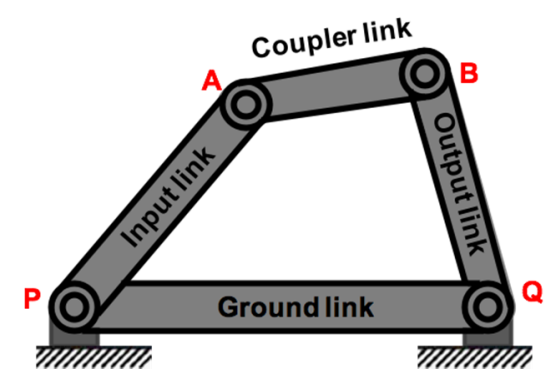

(a)

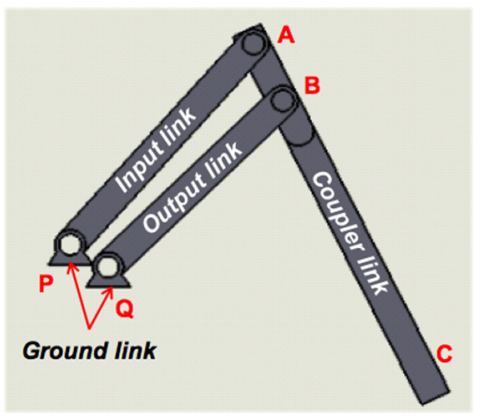

(b)

Figure 7. (a) The basic four-bar linkage and (b) the modified coupler link, which is used for the microtab, extending the coupler link from $\overline{\mathrm{AB}}$ in (a) to $\overline{\mathrm{ABC}}$ in (b).

The mobility of any object or linkage is determined by its degrees of freedom (DOF). According to the Gruebler's equation, $\mathrm{DOF}=3(\mathrm{~N}-1)-2 \mathrm{M}$, where $\mathrm{N}$ is the number of links (including the ground link) and $\mathrm{M}$ is the number of pivot joints. In the application of the four-bar linkage, both $\mathrm{N}$ and $\mathrm{M}$ are equal to four. Thus, $\mathrm{DOF}=1$, and the four-bar linkage microtab possesses one degree of freedom of 
mobility. This means that any given position of the input link results in only one corresponding position for the coupler link. In comparison, a five-bar linkage system has two degrees of freedom, so it requires two specific input links to generate a unique position for the coupler link. The one degree of freedom associated with the four-bar linkage system simplifies the control of the microtab's input and output relation. This is why a four-bar linkage was chosen as the foundation of our new microtab design.

\subsubsection{Increase of the Fully-Deployed Tab Height}

The coupler link of the four-bar linkage was extended longer toward the output link direction (i.e., extends $\overline{\mathrm{AB}}$ in Figure $7 \mathrm{a}$ to $\overline{\mathrm{ABC}}$ in Figure $7 \mathrm{~b}$ ) is the newly-designed microtab. The new microtab, which is deployed into the air flow through the slot on the lower surface of the airfoil in Figure $3 \mathrm{~d}$, is supported by the input and output links. The input link is connected to an actuator, which drives and controls the movement of the system. When the microtab is at its retracted position, it cannot be placed normal to the lower surface since the microtab (its length being longer than $1.7 \%$ chord) is longer than the space in the normal direction (1\% chord). Instead, a tilting angle from the normal direction of the airfoil surface was required to overcome the space limitation. The microtab follows a curved trajectory for deployment and retraction. The movement of the microtab included translation and rotation to achieve a curved trajectory. Generally, in the fully-deployed position, the $\overline{\mathrm{BC}}$ portion (about $1.7 \%$ chord) of the microtab is exposed to air flow outside of the airfoil.

\subsubsection{Improvement on the Microtab's Steadiness and Reliability}

The existing microtab has only a single, long lever arm to support the microtab (Figure 3c). The existing design possesses a weak structure, which is less reliable during and after its deployment under strong wind conditions. Figure 8 shows the three-dimensional spatial structure of the newly-designed microtab. Instead of one long lever arm with one support, the new design uses five links, which consist of three input links and two output links, with five supports. These five input and output links are much shorter compared to the lever arm in the existing microtabs. The input and output links are in an alternative order and are aligned in two planes (input link plane and output link plane). The five links should significantly increase the steadiness and reliability of the microtab structure during and after deployment.

The actuator is connected to the middle of the three input links, which for convenience is named the actuator input bar (Figure 8). The link between the actuator and the actuator input bar is called the actuator transmission bar, which will be further described in the next section.

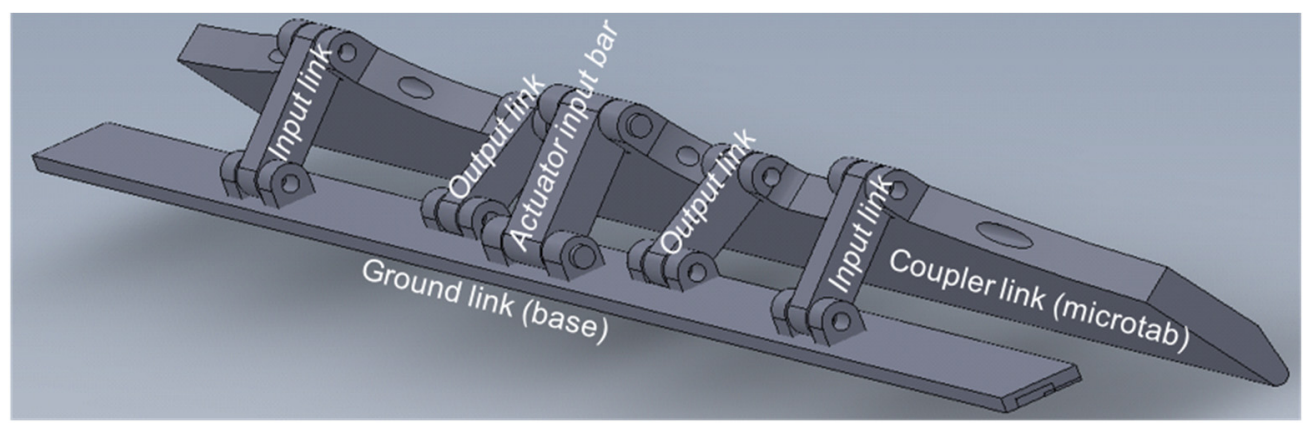

Figure 8. The assembly of the four-bar linkage microtab. 


\subsection{Transformation of the Actuator Input Bar}

As mentioned in Section 4.1, the newly-designed microtab follows a curved trajectory during its deployment and retraction. Then, we transformed the actuator input bar. If no transformation is made to the actuator input bar, the actuator transmission bar has to move along a curved trajectory when it is activated to deploy or retract the microtab. A curved trajectory for the actuator transmission bar movement can complicate the design of the microtab mechanism. In order to keep a simple straight line motion for the actuator transmission bar, we transformed the actuator input bar into a V-shape by adding a dummy side (V-shaped DPA, a V-shaped rigid body which passes points $\mathrm{D}$, P, and A, in Figure 9). For convenience, we name it the transformed actuator input bar. The addition of the dummy side did not affect the motions of the coupler link and output links.

Instead of connecting to Joint A, the actuator transmission bar connects to Joint D of the transformed actuator input bar, which has a straight line slot (Figures 9 and 10). The joint allows the connection point of the actuator transmission bar to freely slide within the slot so that the actuator transmission bar moves along a straight line during deployment or retraction of the microtab (Figure 10).

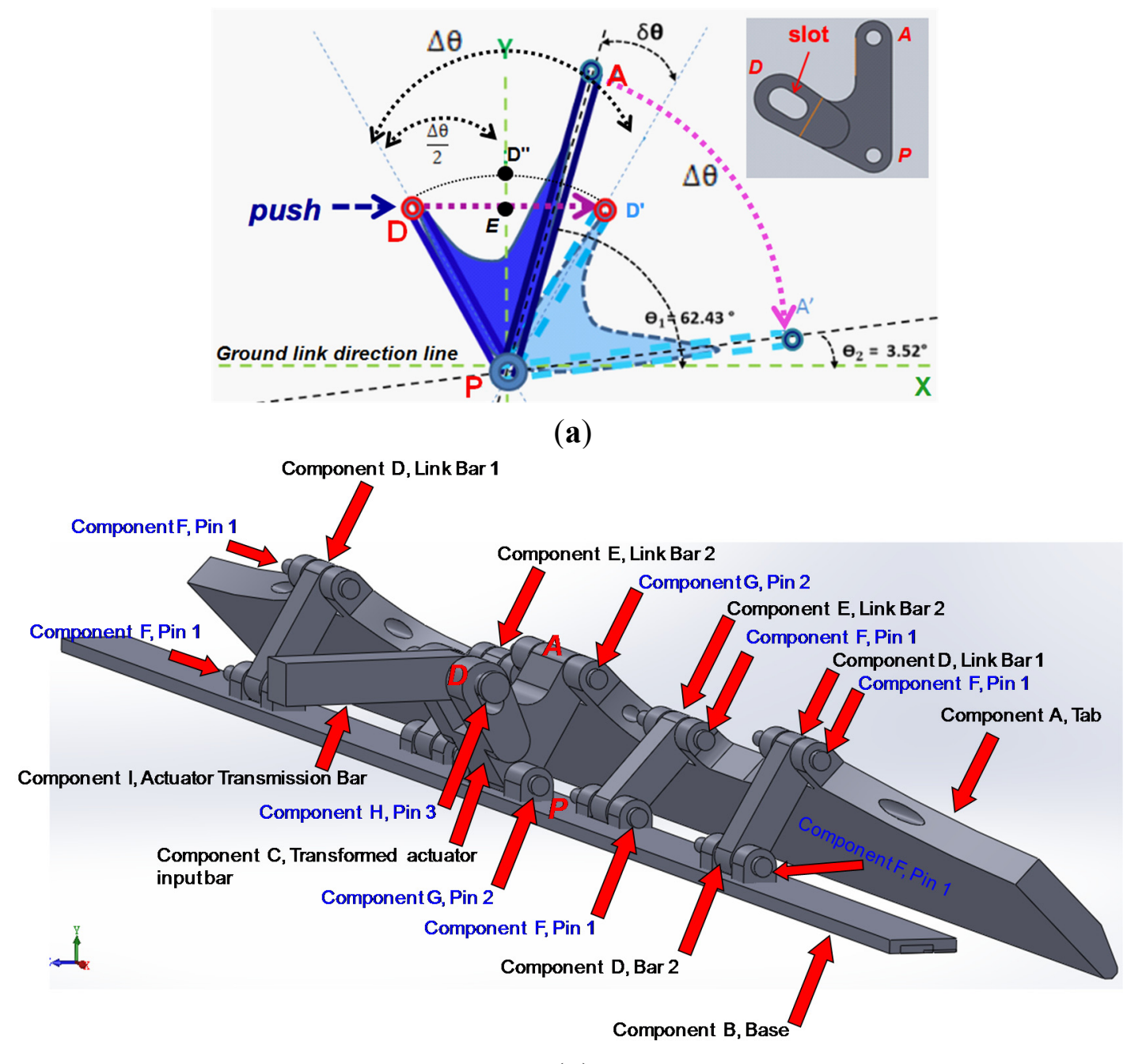

(b)

Figure 9. (a) The geometry relation of the transformed actuator input bar from retraction (V-shaped DPA, a V-shaped rigid body which passes points D, P, and A.) to full 
deployment ( $\mathrm{V}$-shaped $\mathrm{D}^{\prime} \mathrm{PA}^{\prime}$, the same rigid body which passes points $\mathrm{D}^{\prime}, \mathrm{P}$, and $\mathrm{A}^{\prime}$.). Inset: the side view of CAD drawing of the V-shape. (b) The CAD drawing of the new microtab mechanism, including the transformed actuator input bar and the actuator transmission bar.

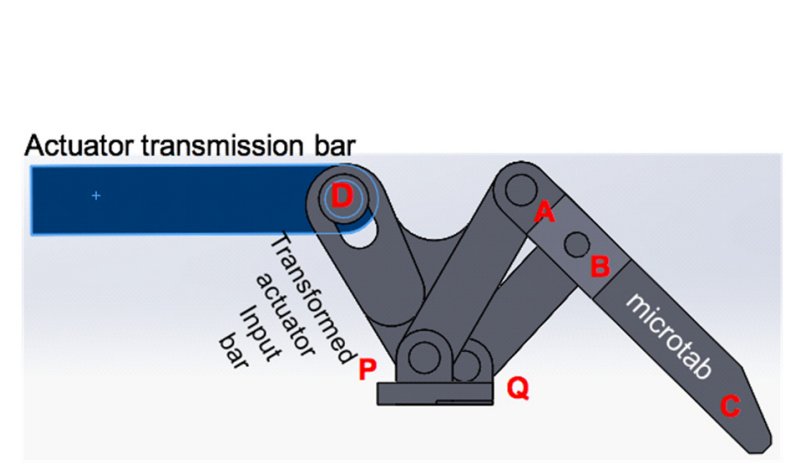

(a)

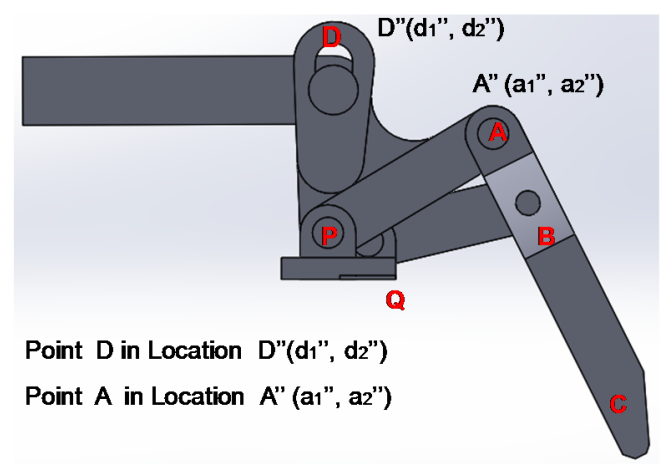

(b)

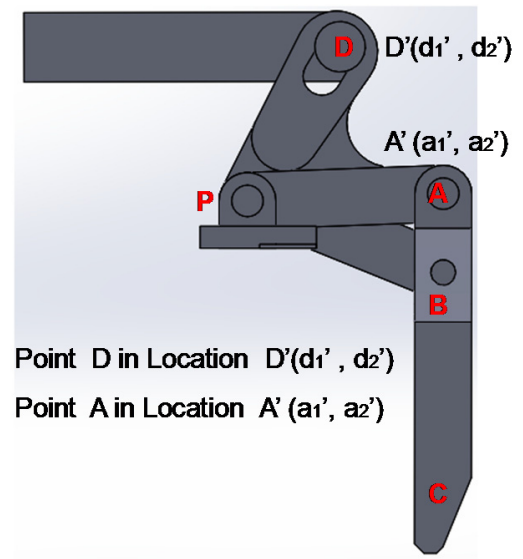

(c)

Figure 10. The CAD drawing of the side view of the new microtab mechanism, including the actuator transmission bar. The microtab (a) at retraction, (b) in the middle of the deployment and (c) after full deployment.

\subsection{Calculation for Slot, Stroke and Force of the Actuator}

In this subsection, the geometry of the mechanism and the force specification of the actuator are studied. We first determine the angular displacement of the actuator input bar (i.e., $\overline{\mathrm{PA}}$ ). The angle between the actuator input bar and the ground link is $\theta$ (Figure 9a). The change of the angle for the input bar from the retracted position $\overline{\mathrm{PA}}\left(\theta_{1}\right)$ to the fully-deployed position $\overline{\mathrm{PA}}\left(\theta_{2}\right)$ is $\Delta \theta\left(=\theta_{1}-\theta_{2}\right)$. For the new microtab, $\theta_{1}=62.43^{\circ}$ and $\theta_{2}=3.52^{\circ}$, and thus, $\Delta \theta=58.91^{\circ}$. From Figure $9 \mathrm{a}$, the angle between $\overline{\mathrm{PD}}$ and $\overline{\mathrm{PD}^{\prime}}$ is also equal to $\Delta \theta$. Since the actuator transmission bar moves along a straight line, an intuitive design is to choose the symmetric line between $\overline{\mathrm{PD}}$ and $\overline{\mathrm{PD}^{\prime}}$, i.e., line $\overline{\mathrm{PD}^{\prime \prime}}$, orthogonal to the moving direction of the actuator transmission bar. As a result, the angle $\angle \mathrm{APD}^{\prime}(\delta \theta)$ is $1.885^{\circ}$ from the examination the geometry relation shown in Figure 9a.

To accommodate the new microtab within the airfoil model and to fully make use of the available space, we designed $\overline{\mathrm{PA}}$, as well as the other two input links, to be $6.2 \mathrm{~mm}$ long. The length of $\overline{\mathrm{PD}}$ is more adjustable, as long as it does not interfere with the inner skin. 
Next, we determine the stroke length of the linear actuator and the slot length on the transformed actuator input bar. As shown in Figure 9a, the stroke of the linear actuator is equal to the distance of $\overline{\mathrm{DD}^{\prime}}$, and the slot on the transformed actuator input bar is equal to $\overline{\mathrm{ED}^{\prime \prime}}$. However, the latter (i.e., the slot) additionally needs to consider the radius of the pins. Thus, the length of the slot is equal to $\overline{\text { ED" }}$ (if we consider the slot's maximum length, two times the radius of the pin must be added). While $\overline{\mathrm{PD}}$ has some flexibility, a length of $5.5 \mathrm{~mm}$ was chosen in this study. As a result, the actuator stroke specification requires a minimum length of $5.409 \mathrm{~mm}$, and the slot on the transformed actuator input bar requires a minimum length of $0.711 \mathrm{~mm}$ (a longer length has no impact on the function of the microtab), as shown in Figures 9 and 10. Figure 11 shows the final configuration of the new microtab mechanism and the actuator transmission bar within the S819 airfoil model.

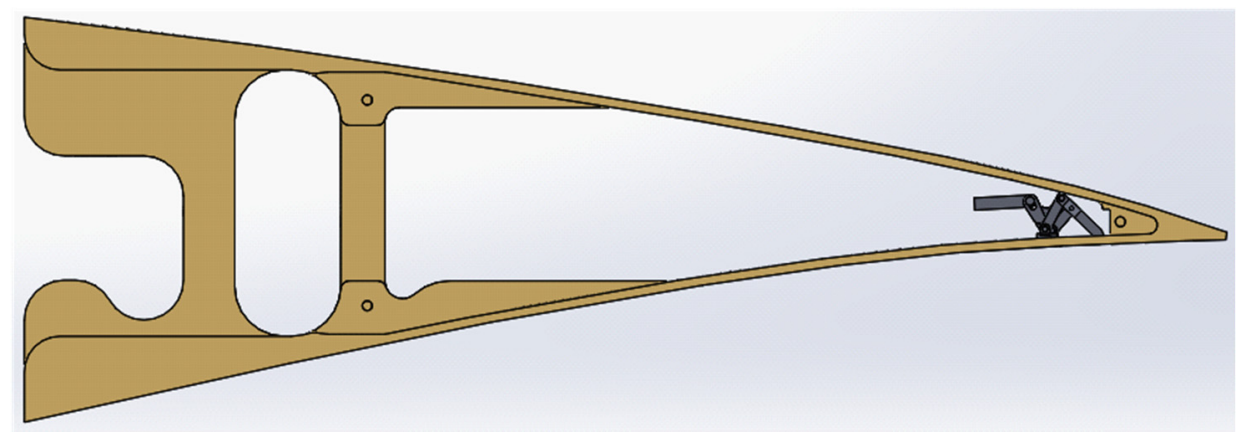

Figure 11. The CAD drawing of the newly-designed microtab mechanism, including the actuator transmission bar, which is installed in the S819 airfoil model.

Lastly, we evaluate the specification force of the actuator required to support the microtab against the wind after it is fully deployed. The maximum wind speed (V) in the test section of the UC Davis Aeronautical Wind Tunnel is $70 \mathrm{~m} \cdot \mathrm{s}^{-1}$. When the wind blows within the wind tunnel, the pressure (p) starts building up against the microtab during its deployment, and the pressure reaches the maximum after the microtab is fully deployed. Under the conditions of maximum wind speed $\left(\mathrm{V}=70 \mathrm{~m} \cdot \mathrm{s}^{-1}\right)$ and a fully-deployed microtab, the dynamic pressure against the tab is approximately $3000 \mathrm{~N} / \mathrm{m}^{2}\left(=1 / 2 \rho V^{2}\right.$, where $\rho=1.224 \mathrm{~kg} \cdot \mathrm{m}^{-3}$ ). Since the area of the microtab when fully deployed is $10.16 \mathrm{~cm}^{2}$, the force against the microtab is $3.05 \mathrm{~N}$. After a free body analysis for $\mathrm{V}$-shaped DPA and $\overline{\mathrm{ABC}}$, the required force specification of the actuator is determined to be $4.7 \mathrm{~N}$. This represents the maximum force requirement for the actuator. The next step is to apply CFD to evaluate the aerodynamic loads on the tab as it is deflected to determine the actuator requirements during the complete deployment cycle.

\section{Conclusions}

In this study, we present a newly-designed microtab that increases fully-deployed tab height and allows for a more robust microtab deployment and support mechanism. The new microtab mechanism was designed based on the concept of the four-bar linkage. The four-bar linkage microtab includes three input links, two output links, one coupler link and one ground link. The coupler link was extended longer and served as the microtab. The design of the transformed actuator input bar allowed the actuator transmission bar to move along a straight line, which simplified the design of the system. Under the new design, the fully-deployed tab height is increased by $70 \%$ to $1.7 \%$ of the airfoil chord. 
In addition, the modified four-bar link mechanism adopted for the new design provides a more robust and reliable mechanical structure.

\section{Acknowledgments}

The authors thank Dr. Shu-Hua Chen at the University of California - Davis for her helpful discussion and insightful comments on the manuscript. We would also like to thank Yi-Jay Tsai and Ziqi Yin for their help with the drawings. The authors also acknowledge financial support by the Sandia National Laboratories and the Warren and Leta Giedt Endowment during various stages of this project.

\section{Author Contributions}

Kuo-Chang Tsai created the innovative design of the microtab mechanism to improve its performance and initiated the article writing. C.P. van Dam guided the microtab research and finalized the manuscript. All authors contributed to the research result, experimental analysis or development of the ideas.

\section{Conflicts of Interest}

The authors declare no conflict of interest.

\section{References}

1. Cooperman, A.M.; Chow, R.; Johnson, S.J.; van Dam, C.P. Experimental and computational analysis of a wind turbine airfoil with active microtabs. In Proceedings of the 49th AIAA Aerospace Sciences Meeting including the New Horizons Forum and Aerospace Exposition, Orlando, FL, USA, 4-7 January 2011; doi:10.2514/6.2011-347.

2. Cooperman, A.M.; Chow, R.; van Dam, C.P. Active load control of a wind turbine airfoil using microtabs. J. Aircr. 2013, 50, 1150-1158.

3. Bach, A.B.; Holst, D.; Nayeri, C.N.; Paschereit, C.O. Transitional effects of active micro-tabs for wind turbine load control. In Proceedings of the ASME Turbo Expo 2013: Turbine Technical Conference and Exposition, San Antonio, TX, USA, 3-7 June 2013; doi:10.1115/GT2013-94369.

4. Johnson, S.J.; Baker, J.P.; van Dam, C.P.; Berg, D. An overview of active load control techniques for wind turbines with an emphasis on microtabs. Wind Energy 2010, 13, 239-253.

5. Baker J.P.; Standish, K.J.; van Dam, C.P. Two-dimensional wind tunnel and computational investigation of a microtab modified airfoil. J. Aircr. 2007, 44, 563-572.

6. Mayda, E.; van Dam, C.P.; Yen Nakafuji, D. Computational investigation of finite width microtabs for aerodynamic load control. In Proceedings of the 43rd AIAA Aerospace Sciences Meeting, Reno, NV, USA, 10-13 January 2005; doi:10.2514/6.2005-1185.

7. Chow, R.; van Dam, C.P. Unsteady computational investigations of deploying load control microtabs. J. Aircr. 2006, 43, 1458-1469.

8. Yen, D.T. Active Load Control Using Microtabs. Ph.D. Dissertation, University of California, Davis, CA, USA, April 2001.

9. Liebeck, R.H. Design of subsonic airfoils for high lift. J. Aircr. 1978, 15, 547-561. 
10. Johnson, S.J. Active Load Control Techniques for Wind Turbines Focusing on Mechanical Design of a Microtab System. MS Thesis, University of California, Davis, CA, USA, March 2008.

11. Yen Nakafuji, D.; van Dam, C.P.; Smith, R.L.; Collins, S.D. Active load control for airfoils using microtabs. Trans. ASME 2001, 123, 282-289.

12. Baker, J.P.; Standish, K.J.; van Dam, C.P. Two-dimensional wind tunnel and computational investigation of a microtab modified S809 airfoil. In Proceedings of the 43rd AIAA Aerospace Sciences Meeting and Exhibit, Reno, NV, USA, 10-13 January 2005; AIAA-2005-1186.

13. Cooperman, A.M. Wind Tunnel Testing of Microtabs and Microjets for Active Load Control of Wind Turbine Blades. Ph.D. Dissertation, University of California, Davis, CA, USA, December 2012.

(C) 2015 by the authors; licensee MDPI, Basel, Switzerland. This article is an open access article distributed under the terms and conditions of the Creative Commons Attribution license (http://creativecommons.org/licenses/by/4.0/). 